Case Report

\title{
Granulomatous Lobular Mastitis Associated with Mycobacterium abscessus in South China: A Case Report and Review of the Literature
}

\author{
Ye-sheng Wang, ${ }^{1}$ Qi-wei Li, ${ }^{1}$ Lin Zhou, ${ }^{1}$ Run-feng Guan, ${ }^{1}$ Xiang-ming Zhou, ${ }^{1}$ \\ Ji-hong Wu, ${ }^{1}$ Nan-yan Rao, ${ }^{2}$ and Shuang $\mathrm{Zhu}^{1}$ \\ ${ }^{1}$ Guangdong Province Key Laboratory for Biotechnology Drug Candidates, School of Biosciences and Biopharmaceutics, \\ Guangdong Pharmaceutical University, Guangzhou, Guangdong 510006, China \\ ${ }^{2}$ Sun Yat-sen Memorial Hospital of Zhongshan University, Guangzhou, Guangdong 510120, China
}

Correspondence should be addressed to Nan-yan Rao; raonany@126.com and Shuang Zhu; 15683727@qq.com

Received 22 November 2016; Accepted 17 January 2017; Published 12 February 2017

Academic Editor: Tomoyuki Shibata

Copyright (C) 2017 Ye-sheng Wang et al. This is an open access article distributed under the Creative Commons Attribution License, which permits unrestricted use, distribution, and reproduction in any medium, provided the original work is properly cited.

Mycobacteria, which are known as rapidly growing bacteria, are pathogens that are responsible for cutaneous or subcutaneous infections that especially occur after injection, trauma, or surgery. In this report, we describe a species of Mycobacterium abscessus that was isolated from a breast abscess in a patient who was previously diagnosed with granulomatous lobular mastitis (GLM). This current case is the first ever presented case of GLM associated with M. abscessus documented in South China. The case presentation highlights the role of M. abscessus in GLM. The association of M. abscessus and GLM is discussed and a summary of breast infection due to Mycobacteria is given.

\section{Introduction}

Granulomatous lobular mastitis (GLM), also known as idiopathic granulomatous mastitis, was first described by Kessler and Wolloch in 1972 [1]. GLM is a rare inflammatory condition of the breast with unknown etiology and variable treatment options [2-5]. Clinically, GLM may be present as a firm, red, tender lesion that suggests the presence of an abscess [6], or as a hard mass closely resembling a malignancy [7]. Although the majority GLM cases appear aseptic [8-10], case reports of documented coinfections with Mycobacterium abscessus have been reported in Turkey [11] and the United States [12]. To our knowledge, the present case is the first ever presented case of GLM associated with M. abscessus that is documented in South China.

\section{Case Report}

A 29-year-old female from South China with a history of swelling, discharge, and chronic abscesses of the right breast for more than 10 days presented to the Department of Breast Surgery in the Second Affiliated Hospital, Sun Yat-sen University, Guangzhou, China. About one month prior, the patient had noted a painful mass in the right breast and a mini-invasive operation was performed. The patient did not have a history of fever, night sweats, weight loss, and respiratory symptoms. In addition, there was no family history of breast cancer and no personal history of tuberculosis. The patient was referred to an outpatient surgery clinic, where a breast ultrasound demonstrated a duct ectasia hypoechoic lobulated mass measuring $16.7 \mathrm{~mm} \times$ $9.8 \mathrm{~mm}$ in the lower quadrant of the right breast and palpable lymph nodes in the ipsilateral axilla. Blood tests showed that full blood count, renal function, liver function, thyroid function, and blood glucose were all within normal limits. The patient was treated with a variety of antibiotics, including doxycycline, clindamycin, and amoxicillin-clavulanic acid for 10 days, without success. The patient underwent drainage of the right breast and $1 \mathrm{ml}$ of purulent fluid was aspirated.

Specimens were sent for routine bacteriology, acid-fast bacteria stain, Gram stain, fungal stains, and culture. Acidfast bacilli were not found, and Gram staining of the pus 


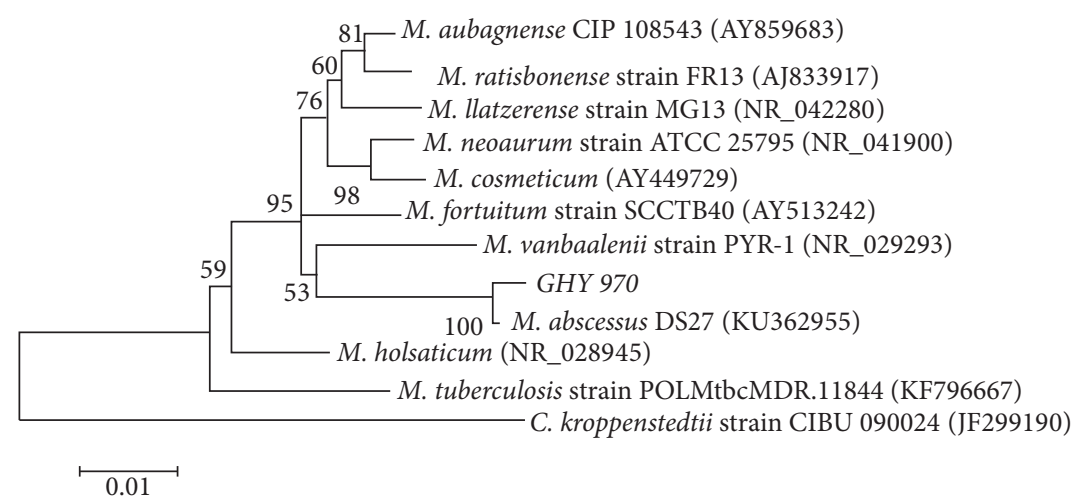

FIGURE 1: Phylogenetic tree based on 16S rDNA gene sequences of GHY 970.

showed that numerous polymorphonuclear leukocytes were present, however, without any organisms. The pus was plated on Columbia agar containing $5 \%$ sheep blood and incubated at $37^{\circ} \mathrm{C}$ in air supplemented with $5 \% \mathrm{CO}_{2}$. Three days after incubation, the presence of strain GHY 970 was confirmed. The colonies that were present on the blood agar plates were identified with 16S rDNA PCR and phylogenetic analysis. Genomic DNA was extracted with the TIANamp Genomic DNA Kit (cat. No. \#DP304-02), according to the manufacturer's guidelines. Bacterial $16 \mathrm{~S}$ rDNAs were amplified by PCR using the combination of a universal primer $1492 \mathrm{r}$ (5' GGT TAC CTT GTT ACG ACT T $3^{\prime}$ ) and bacterial primer $27 f\left(5^{\prime}\right.$ AGA GTT TGA TCC TGG CTC AG $\left.3^{\prime}\right)$. PCR was performed using a thermal cycler with the following cycling parameters: $95^{\circ} \mathrm{C}$ for $5 \mathrm{~min}$ as initial denaturation followed by 30 cycles of $94^{\circ} \mathrm{C}$ for $30 \mathrm{~s}, 55^{\circ} \mathrm{C}$ for $30 \mathrm{~s}, 72^{\circ} \mathrm{C}$ for $1 \mathrm{~min}$, and $72^{\circ} \mathrm{C}$ for $7 \mathrm{~min}$ as final extension. After purification, the amplified products were sent to BGI Company for sequencing analysis. Homology search was performed using BLAST (https://www.ncbi.nlm.nih.gov) and the differences in nucleotide sequences between various bacteria were determined using the sequence alignment editor "BioEdit". Products were further analyzed by MEGA 6.0. The NeighborJoining (NJ) tree was constructed using the Kimura-twoparameter (K2P) distance model. Phylogenetic analysis of the 16S rDNA gene sequence of strain GHY 970 revealed the species of $M$. abscessus (Figure 1). NCBI data search indicated $>99 \%$ sequence identity to the M. abscessus DS27 (KU362955). Because the patient's treatment with antibiotics was discontinued, a new breast nodule appeared in the right breast, and the patient was treated with a combination of rifampicin, isoniazid, and pyrazinamide. After 3 months of treatment, the mass in the right breast and axillary lymph nodes had totally disappeared. The entire treatment therapy was completed by 6 months and, at follow-up after 1 year, there were no signs of recurrence or any other issues.

\section{Discussion}

M. abscessus, a rapidly growing type of Mycobacterium, is abundant in natural and processed water sources as well as in sewage and soil. M. abscessus primarily affects pulmonary, soft tissue and causes disseminated infections [13]. M. abscessus may be present in cases following trauma or surgery after contamination of the wound, medical device implantation, and injection site abscesses. Mycobacteria encompass a broad range of Gram-positive bacilli that are often part of the skin microbiome. Therefore, trying to distinguish between colonization, infection, and contamination is challenging. GLM caused by M. abscessus is extremely rare and only occurs in few cases. We have summarized several cases of breast infection that are due to other Mycobacteria after nipple piercing: four cases of $M$. fortuitum [14-17] and one case of either M. holsaticum, M. agricund, or M. brurnae (Table 1) [18]. Taken together, breast abscesses can be caused by these organisms either before or after surgery.

In the case presented here, M. abscessus was isolated from breast abscess from a patient with GLM. Only few published reports that focus on $M$. abscessus associated with breast infections are available and, to our knowledge, this is the first case of GLM caused by $M$. abscessus in South China. Literature studies confirmed that Mycobacterium was not the only bacterial strain that associates with GLM. Previous studies in the USA and Canada showed that Corynebacteria are commonly detected in GLM $[19,20]$. In addition, a recent study performed in China demonstrated that the predominance of Corynebacteria, especially C. kroppenstedtii, was observed in GLM [21]. In another study it was shown that breast tissue is not sterile but instead contains a diverse population of bacteria. The sources of these bacteria are unknown [22]. Thus, the M. abscessus found in this case may be one of the organisms associated with GLM. Therefore, to elucidate the pathological role of this organism in GLM, further research is warranted.

This case presentation was retrospective and, therefore, lacks a complete data set. However, we found that, in this patient, M. abscessus was associated with GLM. In the initial treatment approach of this patient, treatment with a variety of antibiotics was not successful. This could be due because the patient may be resistant to antibiotics. Therefore, antibiotic treatment was stopped and the patient underwent further clinical examination. It was suggested by clinicians and clinical microbiologists that the source of the Mycobacteria found in this case could be the nonpathogenic components of 
TABLE 1: Cases of breast infection caused by Mycobacteria reported in the literature.

\begin{tabular}{|c|c|c|c|c|c|c|c|c|}
\hline Case & Author, year & Age/ sex & Area (race) & Presentation & Surgery & Organism & $\begin{array}{c}\text { Length of } \\
\text { therapy }\end{array}$ & Outcome \\
\hline 1 & Trupiano, 2001 & $17 / f$ & American & Mass & Resection & M. abscessus & None & $\begin{array}{l}\text { Complete } \\
\text { response }\end{array}$ \\
\hline 2 & Jacobs, 2002 & $35 / \mathrm{f}$ & German & Mass & Open biopsy & $\begin{array}{l}\text { M. holsaticum, } \\
\text { M. agricund, } \\
\text { M. brurnae }\end{array}$ & 10 days & $\begin{array}{l}\text { Complete } \\
\text { response }\end{array}$ \\
\hline 3 & Lewis, 2004 & $29 / f$ & American & Mass & $\begin{array}{l}\text { Core needle } \\
\text { and open } \\
\text { biopsy }\end{array}$ & M. fortuitum & 6 months & $\begin{array}{l}\text { Complete } \\
\text { response }\end{array}$ \\
\hline 4 & $\begin{array}{l}\text { Bengualid, } \\
2008\end{array}$ & $17 / \mathrm{f}$ & American & Abscess & $\begin{array}{l}\text { Incision and } \\
\text { drainage }\end{array}$ & M. fortuitum & $\begin{array}{l}6 \text { to } 12 \\
\text { months }\end{array}$ & $\begin{array}{l}\text { Relapse } \\
\text { after } 3 \\
\text { months }\end{array}$ \\
\hline 5 & Yasar, 2011 & $38 / f$ & Turks & Mass & $\begin{array}{l}\text { Fine needle } \\
\text { aspirations }\end{array}$ & M. abscessus & 4 months & $\begin{array}{l}\text { Complete } \\
\text { response }\end{array}$ \\
\hline 6 & Betal, 2011 & $51 / f$ & Caucasian & Abscess & $\begin{array}{l}\text { Incision and } \\
\text { drainage }\end{array}$ & M. fortuitum & 6 months & $\begin{array}{l}\text { Complete } \\
\text { response }\end{array}$ \\
\hline 7 & Abbass, 2014 & $21 / f$ & Canadian & Mass & Aspiration & M. fortuitum & 6 months & $\begin{array}{l}\text { Complete } \\
\text { response }\end{array}$ \\
\hline 8 & $\begin{array}{l}\text { Present study, } \\
2016\end{array}$ & $29 / f$ & Chinese & Mass & $\begin{array}{c}\text { Core needle } \\
\text { and open } \\
\text { biopsy }\end{array}$ & M. abscessus & 1 year & $\begin{array}{l}\text { Complete } \\
\text { response }\end{array}$ \\
\hline
\end{tabular}

the normal microbiota of the skin flora. After the appearance of a new breast nodule, the patient was cured successfully with rifampicin, isoniazid, and pyrazinamide. Thus, this case presentation highlights the role of $M$. abscessus in GLM and should be targeted for optimal treatment therapy of GLM.

In addition to our study, eight cases of Mycobacteria were reviewed. M. abscessus and other Mycobacteria should be kept in mind when patients with chronic breast or soft tissue infections including recurrent breast abscess do not respond to standard antibiotic therapy. In conclusion, we report a patient with a breast abscess that is caused by M. abscessus. Drainage and a prolonged course of rifampicin, isoniazid, and pyrazinamide therapy were essential for successful treatment.

\section{Competing Interests}

The authors declare that they have no conflict of interests.

\section{References}

[1] E. Kessler and Y. Wolloch, "Granulomatous mastitis: a lesion clinically simulating carcinoma," American Journal of Clinical Pathology, vol. 58, no. 6, pp. 642-646, 1972.

[2] A. F. Azlina, Z. Ariza, T. Arni, and A. N. Hisham, "Chronic granulomatous mastitis: diagnostic and therapeutic considerations," World Journal of Surgery, vol. 27, no. 5, pp. 515-518, 2003.

[3] A. Akcan, H. Akyildiz, M. A. Deneme, H. Akgun, and Y. Aritas, "Granulomatous lobular mastitis: a complex diagnostic and therapeutic problem," World Journal of Surgery, vol. 30, no. 8, pp. 1403-1409, 2006.

[4] M. M. Baslaim, H. A. Khayat, and S. A. Al-Amoudi, "Idiopathic granulomatous mastitis: a heterogeneous disease with variable clinical presentation," World Journal of Surgery, vol. 31, no. 8, pp. 1677-1681, 2007.

[5] B. Al-Khaffaf, F. Knox, and N. J. Bundred, "Idiopathic granulomatous mastitis: a 25-year experience," Journal of the American College of Surgeons, vol. 206, no. 2, pp. 269-273, 2008.

[6] J. Pouchot, E. Foucher, M. Lino, J. Barge, and P. Vinceneux, "Granulomatous mastitis: an uncommon cause of breast abscess," Archives of Internal Medicine, vol. 161, no. 4, pp. 611612, 2001.

[7] C. H. Yip, G. Jayaram, and M. Swain, "The value of cytology in granulomatous mastitis: a report of 16 cases from Malaysia," Australian and New Zealand Journal of Surgery, vol. 70, no. 2, pp. 103-105, 2000.

[8] A. Fletcher, I. M. Magrath, R. H. Riddell, and I. C. Talbot, "Granulomatous mastitis: a report of seven cases," Journal of Clinical Pathology, vol. 35, no. 9, pp. 941-945, 1982.

[9] A. Sellitto, A. Santoriello, U. De Fanis et al., "Granulomatous lobular mastitis: another manifestation of systemic lupus erythematosus?" The Breast Journal, vol. 19, no. 3, pp. 331-332, 2013.

[10] B. Bercot, C. Kannengiesser, C. Oudin et al., "First description of NOD2 variant associated with defective neutrophil responses in a woman with granulomatous mastitis related to corynebacteria," Journal of Clinical Microbiology, vol. 47, no. 9, pp. 30343037, 2009.

[11] K. K. Yasar, F. Pehlivanoglu, G. Sengoz, and N. Cabioglu, "Successfully treated Mycobacterium abscessus mastitis: a rare cause of breast masses," Indian Journal of Medical Microbiology, vol. 29, no. 4, pp. 425-427, 2011.

[12] J. K. Trupiano, B. A. Sebek, J. Goldfarb, L. R. Levy, G. S. Hall, and G. W. Procop, "Mastitis due to Mycobacterium abscessus after body piercing," Clinical Infectious Diseases, vol. 33, no. 1, pp. 131134,2001 
[13] B. Petrini, "Mycobacterium abscessus: an emerging rapidgrowing potential pathogen," APMIS, vol. 114, no. 5, pp. 319-328, 2006.

[14] C. G. Lewis, M. K. Wells, and W. C. Jennings, "Mycobacterium fortuitum breast infection following nipple-piercing, mimicking carcinoma," Breast Journal, vol. 10, no. 4, pp. 363-365, 2004.

[15] V. Bengualid, V. Singh, H. Singh, and J. Berger, "Mycobacterium fortuitum and anaerobic breast abscess following nipple piercing: case presentation and review of the literature," Journal of Adolescent Health, vol. 42, no. 5, pp. 530-532, 2008.

[16] D. Betal and F. A. MacNeill, "Chronic breast abscess due to Mycobacterium fortuitum: a case report," Journal of Medical Case Reports, vol. 5, article 188, 2011.

[17] K. Abbass, M. K. Adnan, R. J. Markert, M. Emig, and N. A. Khan, "Mycobacterium fortuitum breast abscess after nipple piercing," Canadian Family Physician, vol. 60, no. 1, pp. 51-52, 2014.

[18] V. R. Jacobs, K. Golombeck, W. Jonat, and M. Kiechle, “Three case reports of breast abscess after nipple piercing: underestimated health problems of a fashion phenomenon," Zentralblatt fur Gynakologie, vol. 124, no. 7, pp. 378-385, 2002.

[19] G. B. Taylor, S. D. Paviour, S. Musaad, W. O. Jones, and D. J. Holland, "A clinicopathological review of 34 cases of inflammatory breast disease showing an association between corynebacteria infection and granulomatous mastitis," Pathology, vol. 35, no. 2, pp. 109-119, 2003.

[20] T. J. Hieken, J. Chen, T. L. Hoskin et al., "The microbiome of aseptically collected human breast tissue in benign and malignant disease," Scientific Reports, vol. 6, Article ID 30751, 2016.

[21] H. Yu, H. Deng, J. Ma et al., "Clinical metagenomic analysis of bacterial communities in breast abscesses of granulomatous mastitis," International Journal of Infectious Diseases, vol. 53, pp. 30-33, 2016.

[22] C. Urbaniak, J. Cummins, M. Brackstone et al., "Microbiota of human breast tissue," Applied and Environmental Microbiology, vol. 80, no. 10, pp. 3007-3014, 2014. 


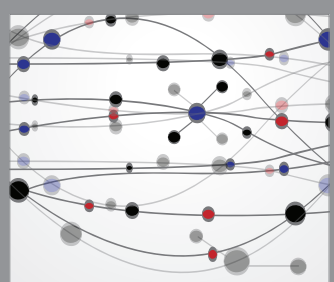

The Scientific World Journal
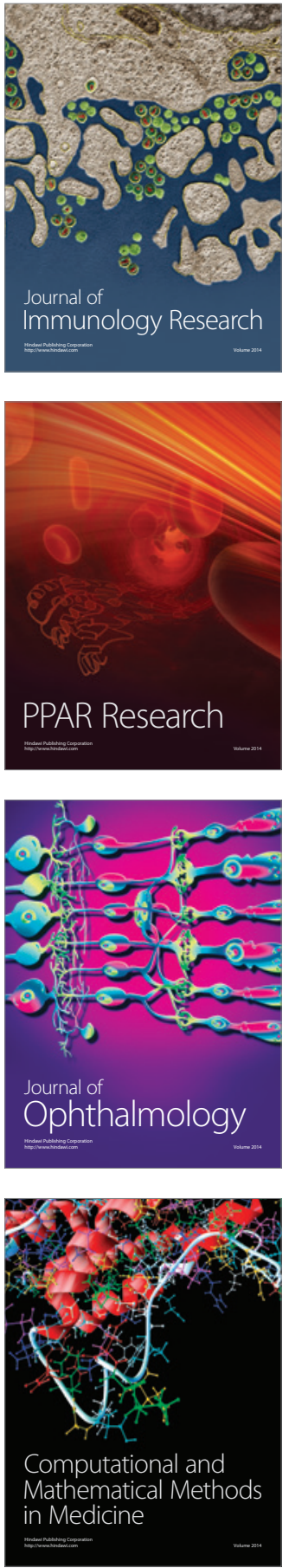

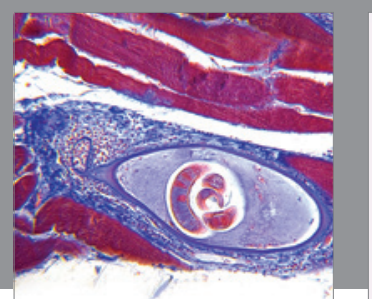

Gastroenterology Research and Practice
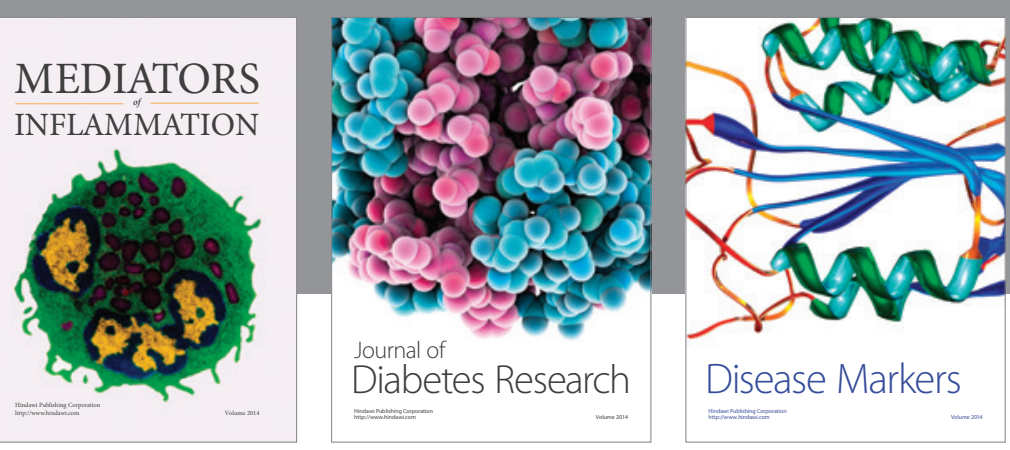

Disease Markers

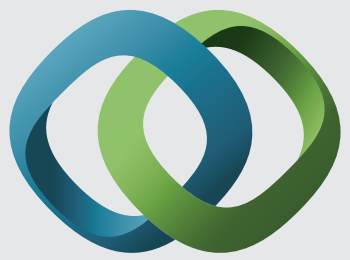

\section{Hindawi}

Submit your manuscripts at

https://www.hindawi.com
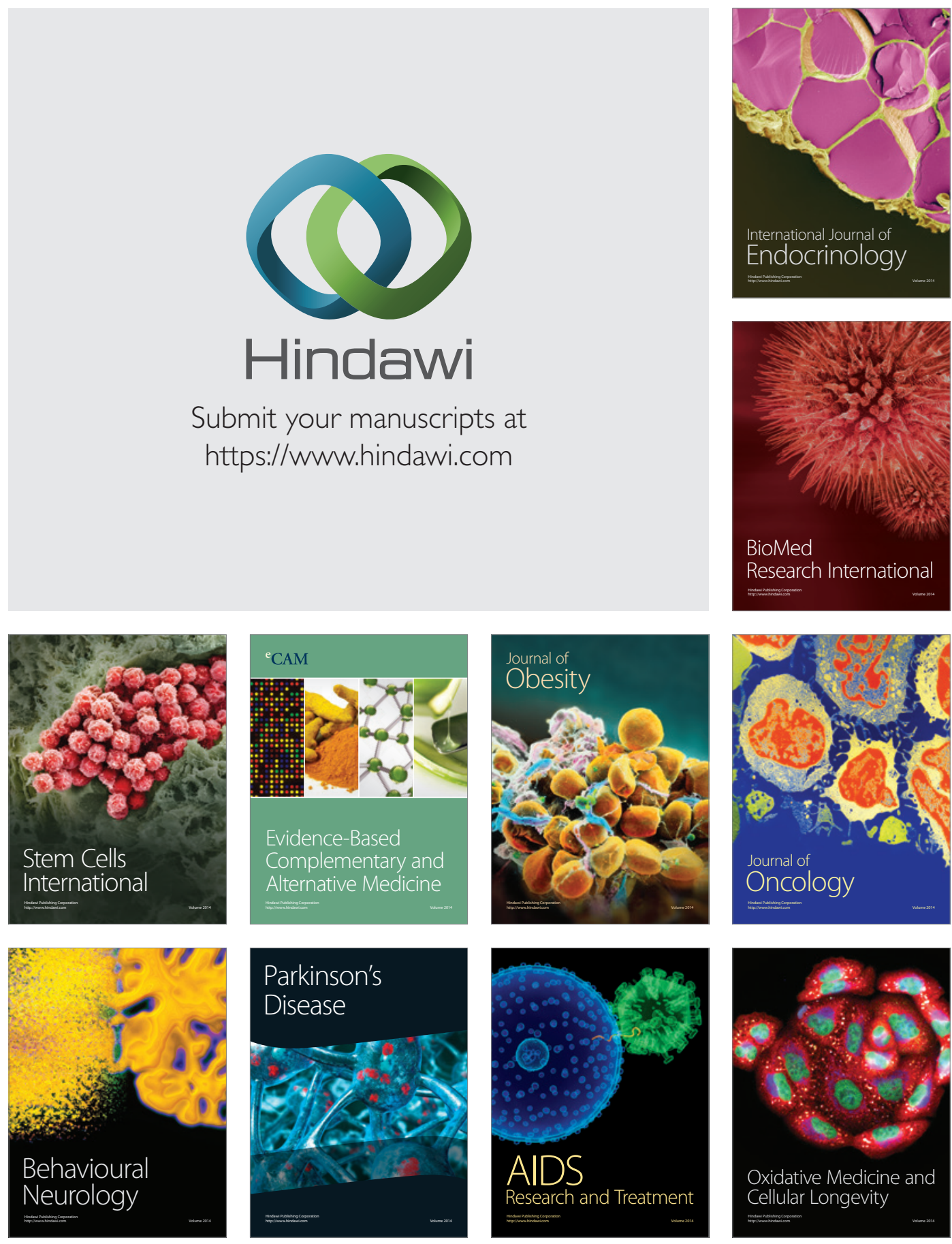